\title{
Efficacy and safety of radiofrequency ablation for benign thyroid nodules in patients with previous thyroid lobectomy
}

\author{
Lin Yan, Mingbo Zhang, Fang Xie, Jun Ma, Jing Xiao and Yukun Luo*
}

\begin{abstract}
Background: Radiofrequency ablation (RFA) is recommended for the treatment of benign thyroid nodules. However, data on the clinical role of RFA for benign thyroid nodules in patients with history of thyroid lobectomy are insufficient. The purpose of this study was to evaluate the efficacy and safety of radiofrequency ablation (RFA) for benign thyroid nodules in patients who had previously undergoing thyroid lobectomy.

Methods: From May 2015 to October 2018, a total of 20 patients (19 females, 1 male, mean age $49.50 \pm 14.26$ years, range 22-74 years) with 20 benign thyroid nodules (mean volume $15.04 \pm 21.17 \mathrm{ml}$, range 0.40-69.67 ml) who had undergone previous thyroid lobectomy were included in this retrospective study. Patients were followed up at 3, 6, 12 months after RFA and every 12 months thereafter by ultrasound, clinical evaluation and thyroid function. Volume, volume reduction rate (VRR), symptom score and cosmetic score were evaluated.
\end{abstract}

Results: During the mean follow-up time of $21.24 \pm 16.41$ months, the mean nodule volume decreased significantly from $15.04 \pm 21.17 \mathrm{ml}$ to $1.29 \pm 1.17 \mathrm{ml}(P=0.018)$ with a mean VRR of $85.41 \pm 12.17 \%$. Therapeutic success was achieved in a single session for all thyroid nodules. The symptom score $(P=0.001)$ and cosmetic score $(P=0.001)$ were both significantly reduced at the last follow-up. The levels of free triiodothyronine (fT3), free thyroxine (fT4) and thyroid stimulating hormone were not significantly different at the last follow-up from those prior to treatment (all $P>0.05$ ). No life-threatening complications or sequelae occurred after RFA.

Conclusions: As a minimally invasive modality, RFA was a safe, effective, and thyroid function-preserving option for patients with symptomatic benign thyroid nodules after a previous lobectomy.

Keywords: Thyroid, Benign thyroid nodule, Radiofrequency ablation, Ultrasound, Volume reduction rate

\section{Background}

Thyroid nodules are common in the general population and occur in $20-70 \%$ of individuals [1]. Thyroid lobectomy or nodule resection is the standard treatment according to the size of nodules [2]. However, after the initial surgery, some patients may develop another nodule with symptomatic or cosmetic problems and also require

*Correspondence: lyk301@163.com; lyk301@yeah.net Department of Ultrasound, First Medical Center, Chinese PLA General Hospital, No. 28 Fuxing Road, Haidian District, Beijing, China reoperation [3]. The incidence of complications during the reoperation, such as recurrent laryngeal nerve (RLN) injury and hypoparathyroidism is much higher than during the initial surgery because of the distorted anatomy of the thyroid and postoperative adhesions [4-6]. Additionally, patients often need thyroid hormone supplementation after the reoperation, which may have adverse effects on the bones and the cardiovascular system [2]. Therefore, the treatment of benign thyroid nodules in patients with previous thyroid lobectomy often poses a dilemma for both patients and physicians. 
Radiofrequency ablation (RFA) and other thermal ablation techniques, such as microwave ablation, laser ablation and high-intensity focused ultrasound (HIFU) ablation have been recommended as safe and effective treatments for benign thyroid nodules by guidelines [2, 7-12]. Several studies have reported a significant reduction in the volume of the nodules along with an improvement in local symptoms or cosmetic problems [13-21]. A meta-analysis reported that the volume reduction rates (VRR) for benign thyroid nodules at 6, 12 and 24 months after RFA were $68 \%, 75 \%$ and $87 \%$, respectively [17]. Moreover, a longitudinal 5-year observational study showed that VRR was $81 \%, 75 \%$, and $65 \%$ for nodules $<10 \mathrm{ml}, 10$ to $20 \mathrm{ml}$ and $>20 \mathrm{ml}$, respectively [22], suggesting that the VRR differed depending on the initial volume. However, for patients with benign thyroid nodules after previous lobectomy, only two studies have reported the clinical outcomes of RFA. Ha et al. [23] found that the nodule volume was $9.7 \mathrm{ml}$ in patients who had undergone previous lobectomy before RFA, which decreased significantly at the last follow-up with a mean VRR of $87.2 \%$. Kim et al. [24] reported the benign thyroid goiter developed after unilateral lobectomy decreased significantly from $4.49 \pm 0.99 \mathrm{ml}$ to $1.05 \pm 0.6 \mathrm{ml}$ with a mean VRR of $81.2 \pm 10.5 \%$. Although the volume reduction after RFA was significant in these two studies, the initial volume was small $(<10 \mathrm{ml})$. Consequently, additional information about the clinical application of RFA for benign thyroid nodules with a larger volume in patients with previous lobectomy is needed.

Therefore, the purpose of this study was to evaluate the efficacy and safety of RFA for benign thyroid nodules in patients with a history of lobectomy.

\section{Methods}

The Institutional Review Board of Chinese PLA General Hospital approved this retrospective study. All the patients were provided written information consent before RFA.

\section{Patients}

Postoperative thyroid nodule was defined as new lesion in the remnant tissue or enlargement in the remaining contralateral lobe after initial surgery [25]. All the enrolled patients fulfilled the following criteria: (1) nodules should be confirmed as benign via two separated fine-needle aspiration (FNA) or core-needle biopsy (CNB); (2) no suspicious malignant features on ultrasound (US) $[2,26]$; (3) underwent initial thyroid surgery for benign thyroid nodule; (4) complaint of cosmetic or symptomatic problems or concerns of nodules growing rapidly or malignant transformation; (5) follow-up time $\geq 6$ months. The exclusion criteria were: (1) follicular neoplasm or malignancy findings on US-guided FNA or CNB; (2)postoperative nodule with benign result in biopsy but was suspected of malignancy in US; (3) contra-lateral vocal cord paralysis; (4) coagulation disorder or serious heart failure/ respiratory failure/ liver failure/ renal failure; (5) follow-up time $<6$ months.

From May 2015 to October 2018, 22 patients with benign nodules who had a history of thyroid lobectomy underwent RFA in this institution. Among them, patients with follow-up time $<6$ months $(\mathrm{N}=2)$ were excluded. The remaining 20 patients with 20 benign nodules were included in this study.

\section{Pre-ablation assessment}

All the patients underwent laboratory tests included complete blood count, coagulation tests and thyroid function tests. The thyroid function tests included free triiodothyronine (fT3, normal range 2.76-6.30 pmol/l), free thyroxine (fT4, normal range 10.42-24.32 pmol/l) and thyroid stimulating hormone $\mathrm{TSH}$, normal range 0.23-5.50 mU/l). Before treatment, each nodule underwent US to assess the size, location, component, margin, shape, echogenicity, calcification and vascularity. The volume of thyroid nodules was calculated with the equation: $\mathrm{V}=\pi \mathrm{abc} / 6$ (V is the volume, while a is the largest diameter, $b$ and $c$ are the other two perpendicular diameters) [27]. The nodules were further categorized into three subgroups according to volume as the small (i.e., $<10 \mathrm{ml}$, $\mathrm{N}=12$ ), medium (i.e., $10-30 \mathrm{ml}, \mathrm{N}=5$ ), and large (i.e., $>30 \mathrm{ml}, \mathrm{N}=3$ ) groups [27]. Before RFA, symptom score was self-measured by patients using a $10-\mathrm{cm}$ visual analogue scale (grade 0-10) [7]. The cosmetic score was assessed by a physician (1, no palpable mass; 2 , no cosmetic problem but palpable mass; 3 , a cosmetic problem on swallowing only; and 4 , a readily detected cosmetic problem) [7].

\section{RFA procedure}

US and contrast-enhanced ultrasound (CEUS) before and after RFA, as well as during follow-up were performed using a Siemens Acuson Sequoia 512 Ultrasound System (Siemens, Mountain View) with a $15 \mathrm{~L} 8 \mathrm{~W}$ linear array transducer or a Philips iU22 Ultrasound System (Philips Healthcare) with a L12-5 linear array transducer or a Mindray M9 Ultrasound System (Mindray) with a L12-4 linear array transducer. US-guided FNA or CNB and RFA were all performed using a Siemens Acuson Sequoia 512 Ultrasound System with a 6L3 linear array transducer.

CEUS was performed to assess the blood supply of the nodule before and immediately after ablation. The US contrast agent was sulphur hexafluoride (SonoVueR, $2.4 \mathrm{ml}$ ) followed by a $5 \mathrm{ml}$ normal saline flush. All RFA procedures were performed by an experienced 
US physician with more than 20-year experience in interventional thyroid US. A bipolar RFA generator (CelonLabPOWER, Olympus Surgical Technologies Europe) and an 18-gauge bipolar RF electrodes with $0.9 \mathrm{~cm}$ active tip were used (CelonProSurge micro 100T09, Olympus Surgical Technologies Europe) in this study (Fig. 1).

Patients were placed an operating table in the supine position with neck extended. Local anesthesia with $1 \%$ lidocaine was administered. The hydrodissection technique was usually used if the distance between the tumor and critical cervical structures (trachea, cervical artery, jugular vein, esophagus and recurrent laryngeal nerve) was $<5 \mathrm{~mm}$ [7]. Considering the nodular volume, distorted anatomy and postoperative adhesions caused by the previous surgery, this technique was performed to all the patients in this study. The RFA power was $3 \mathrm{~W}$. If a transient hyperechoic zone did not form at the electrode tip within 5-10 s, the radiofrequency power was increased to 5-9 W [28]. CEUS was performed immediately after the RFA procedure to evaluate the ablation area. If any enhancement existed, a complementary ablation could be performed [28]. During the procedure, special attention was given to the protection of critical cervical structures in order to prevent thermal injury or complication. Each patient was observed for $2 \mathrm{~h}$ in the hospital while any complication
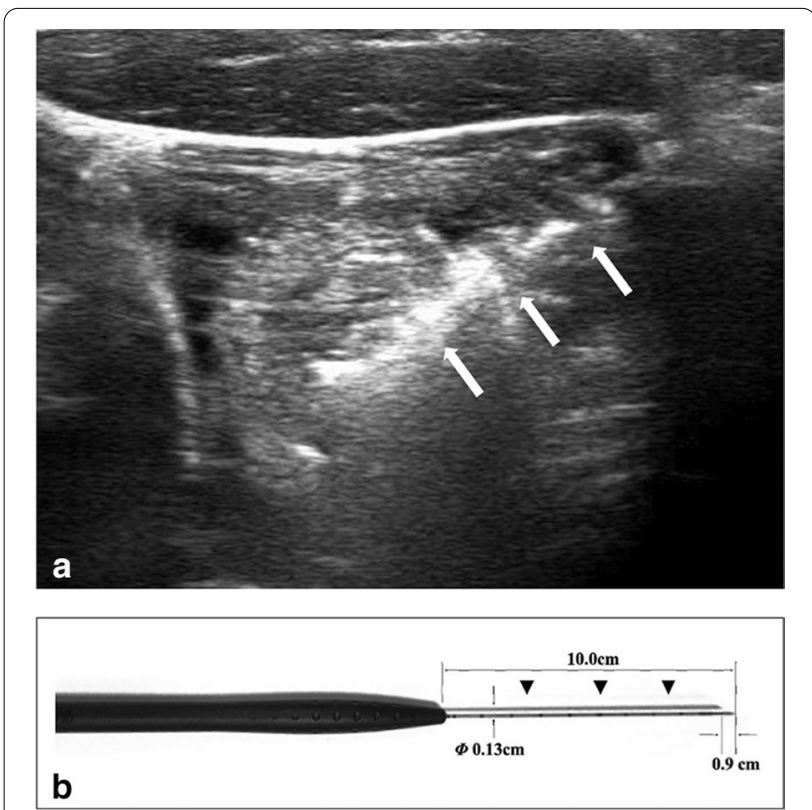

Fig. 1 The 18-gauge bipolar RFA needle used in this study. The ultrasound image of the 18-gauge bipolar RFA needle (arrows) during the RFA procedure for benign thyroid nodules (a). The needle had insulated metallic sheath (arrowheads) and the active tip was $0.9 \mathrm{~cm}$ (b) occurring during and immediately after ablation were carefully evaluated according to the clinical signs and symptoms [28].

After RFA, patients were followed up at 3, 6, 12 months and every 12 months thereafter and underwent periodic US, clinical evaluation and thyroid function. Symptom scores, cosmetic scores and complications after RFA were evaluated at each follow-up. The volume reduction was calculated as follows: VRR $=$ ([initial volume-final volume] $\times 100 \%$ /initial volume [27]. Therapeutic efficacy was defined as a $>50 \%$ volume reduction at last followup [27]. Regrowth was defined as the nodule volume increased $>50 \%$ compared to the previously recorded volume $[27,29]$. Additional ablation may be considered if the nodule showed marginal regrowth or if cosmetic or symptomatic problems were incompletely resolved [7].

\section{Statistical analysis}

Statistical analysis was performed using the SPSS statistical software (Version 25.0). Continuous data were expressed as mean \pm SD (range). Wilcoxon signed rank tests were used to compare the mean volume, symptom and cosmetic scores before RFA and at each follow-up point after RFA. A difference with $P<0.05$ was considered as statistically significant.

\section{Results}

\section{Patient characteristics}

Clinical characteristics of patients before RFA are presented in Table 1. A total of 20 patients (19 females, 1 male) with 20 benign thyroid nodules who had a history

Table 1 Clinical characteristics of patients before RFA

\begin{tabular}{ll}
\hline Characteristics & Data \\
\hline No. of patients & 20 \\
No. of nodules & 20 \\
Age (years) & $49.50 \pm 14.26$ \\
Sex (F/M) & $19 / 1(95.00 / 5.00)$ \\
largest diameter (cm) & $3.18 \pm 1.46$ \\
Mean volume $(\mathrm{ml})$ & $15.04 \pm 21.17$ \\
Small $(\mathrm{N}=12)$ & $4.24 \pm 3.63$ \\
Medium $(\mathrm{N}=5)$ & $12.90 \pm 1.66$ \\
Large $(\mathrm{N}=3)$ & $61.83 \pm 13.56$ \\
Location & \\
Right lobe & $10(50.00)$ \\
Left lobe & $9(45.00)$ \\
Isthmus & $1(5.00)$ \\
Hypothyroidism before treatment & $1(5.00)$
\end{tabular}

Values are presented as mean $\pm S D$ (range) or number of tumors (percentages) RFA radiofrequency ablation 
of thyroid lobectomy were included in this study. The mean age was $49.50 \pm 14.26$ years. The mean initial volume was $15.04 \pm 21.17 \mathrm{ml}$.

In RFA procedure, power of $3 \mathrm{~W}$ was used in 2 nodules; $5-6 \mathrm{~W}$ was used in 7 nodules; 7-8 W was used in 7 nodules and $9 \mathrm{~W}$ was used in 4 nodules. The mean RFA time was $365 \pm 182.50 \mathrm{~s}$ and the mean energy was $2337.89 \pm 1379.74 \mathrm{~J}$. The mean energy applied per volume was $628.79 \pm 861.45 \mathrm{~J} / \mathrm{ml}$.

\section{Efficacy}

The volume and VRR at each follow-up point after RFA are summarized in Table 2. The mean volume decreased significantly from $15.04 \pm 21.17 \mathrm{ml}$ to $1.29 \pm 1.17 \mathrm{ml}$. The VRR was $62.81 \pm 21.56 \%, 74.83 \pm 13.44 \%, 81.65 \pm 13.59 \%$ and $85.42 \pm 12.16 \%$ at $3,6,12$ and 24 months, respectively. All the nodules underwent a single session, and the therapeutic efficacy rate was $100 \%$. The VRR was $86.71 \pm 14.11 \%, 82.19 \pm 7.95 \%$, and $75.65 \pm 3.73 \%$ in the small, medium, and large group, respectively (Table 3). No regrowth was found after RFA. Two nodules (10.00\%) in the small group were disappeared during the follow-up. At the last follow-up, the symptom scores significantly decreased from $3.00 \pm 2.64$ to $0.90 \pm 1.33$ $(P=0.001)$, and the cosmetic scores significantly decreased from $2.40 \pm 1.23$ to $1.40 \pm 0.60(P=0.001)$.

The changes of fT3, fT 4 and TSH are before RFA and at last follow-up were summarized in Table 4. The thyroid function was well-maintained after RFA and no patient developed hypothyroidism. A representative case before and after RFA is shown in Fig. 2.

\section{Safety}

All the patients tolerated the RFA procedure. No patients had complications during or after RFA. Side effects like pain and discomfort occurred in 8 patients, which resolved spontaneously within 3 days.

\section{Discussion}

This study showed that during a mean follow-up time of $21.24 \pm 16.41$ months, the mean VRR of benign nodules in patients with previous lobectomy was $85.41 \pm 12.17 \%$, while the therapeutic efficacy rate was $100 \%$. All

Table 2 Changes of volume and VRR at each follow-up after RFA

\begin{tabular}{lcll}
\hline Time (months) & Volume $(\mathrm{ml})$ & $\begin{array}{l}P \text { value } \\
\text { (vs initial volume) }\end{array}$ & $\begin{array}{l}\text { VRR } \\
(\%)\end{array}$ \\
\hline 3 & $11.53 \pm 16.88$ & 0.005 & $62.81 \pm 21.56$ \\
6 & $6.24 \pm 8.74$ & 0.002 & $74.83 \pm 13.44$ \\
12 & $3.94 \pm 5.70$ & 0.003 & $81.65 \pm 13.59$ \\
24 & $1.29 \pm 1.17$ & 0.018 & $85.42 \pm 12.16$ \\
\hline
\end{tabular}

RFA: radiofrequency ablation
Table 3 Changes of VRR in subgroups at each follow-up after RFA

\begin{tabular}{llll}
\hline $\begin{array}{l}\text { Time } \\
\text { (months) }\end{array}$ & $\begin{array}{l}\text { Small group } \\
(\mathrm{N}=12)\end{array}$ & $\begin{array}{l}\text { Medium group } \\
(\mathrm{N}=5)\end{array}$ & $\begin{array}{l}\text { Large group } \\
(\mathrm{N}=3)\end{array}$ \\
\hline 3 & $73.73 \pm 25.93$ & $60.82 \pm 9.57$ & $50.22 \pm 22.58$ \\
6 & $79.01 \pm 16.96$ & $72.35 \pm 11.59$ & $68.95 \pm 5.20$ \\
12 & $85.29 \pm 16.22$ & $74.93 \pm 0.82$ & $75.65 \pm 3.73$ \\
24 & $86.71 \pm 14.11$ & $82.19 \pm 7.95$ & $\mathrm{NA}$ \\
\hline
\end{tabular}

$N A$ : not available

VRR: reduction volume rate, RFA radiofrequency ablation

nodule-related symptoms and cosmetic problems showed clinical improvement without the occurrence of any lifethreatening complications or sequelae after RFA. Moreover, thyroid function was well-maintained after RFA, and no patient developed hypothyroidism. These results demonstrated that RFA was a safe, effective and thyroid function preserving treatment for patients with previous lobectomy, even for large thyroid nodules $(>10 \mathrm{ml})$.

Although RFA and other thermal ablation techniques has been considered as effective treatments for benign thyroid nodule [2, 7-12], evidence regarding the clinical outcomes of ablation for nodules in patients with previous lobectomy was limited. Ha et al. [23] first reported that the nodule volume was $9.7 \mathrm{ml}$ in patients who had undergone lobectomy before RFA, and it was significantly decreased at the last follow-up with a mean VRR of $87.2 \%$. Kim et al. [24] found that RFA resulted in a mean VRR of $81.2 \pm 10.5 \%$ in patients with a benign thyroid goiter who had a history of unilateral lobectomy. A similar VRR was also observed in this study $(85.41 \pm 12.17 \%)$ after a mean follow-up time of $21.24 \pm 16.41$ months. Compared with previous studies that only included small volume nodules $(<10 \mathrm{ml})[23,24]$, the initial volume in this study was much larger $(15.04 \pm 21.17 \mathrm{ml})$. Moreover, the therapeutic efficacy rate in every group was $100 \%$, and all nodule-related symptoms and cosmetic problems showed clinical improvement. These results indicated that RFA of larger $(>10 \mathrm{ml})$ nodules in patients with previous lobectomy was also effective.

Table 4 The changes of fT3, fT4 and TSH before RFA and at last follow-up

\begin{tabular}{lrrr}
\hline & \multicolumn{1}{c}{ Baseline } & At last follow-up & $P$ value \\
\hline fT3 & $4.98 \pm 0.87$ & $4.67 \pm 0.51$ & 0.180 \\
fT4 & $16.41 \pm 4.41$ & $15.24 \pm 2.12$ & 0.655 \\
TSH & $1.22 \pm 0.69$ & $1.67 \pm 0.74$ & 0.180 \\
\hline
\end{tabular}

fT3 free triiodothyronine, normal range $2.76-6.30 \mathrm{pmol} / \mathrm{l}$, fT4 free thyroxine, normal range 10.42-24.32 pmol/l, TSH thyroid stimulating hormone, normal range $0.23-5.50 \mathrm{mU} / \mathrm{l}, R F A$ radiofrequency ablation 

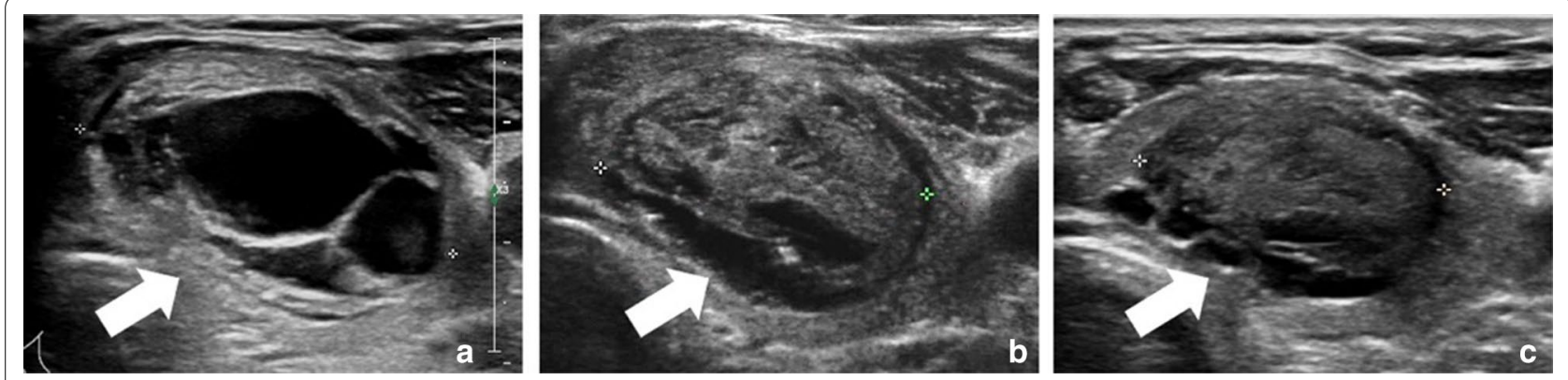

Fig. 2 US images of a postoperative thyroid nodule. a The transverse US showed a postoperative nodule at the left lobe. Before RFA, the initial volume was $11.95 \mathrm{ml}$. b At 3 months after RFA, the volume of nodule was $5.43 \mathrm{ml}$. C. At 12 months after RFA, the volume shrunk to $2.92 \mathrm{ml}$

Although reoperation is the standard treatment for postoperative symptomatic benign nodules, it is associated with a high incidence of complications because of the normal tissue plane distortion and scar formation due to the initial surgery $[4,5,30,31]$. RLN injury and hypoparathyroidism are the major complications. Hardman et al. [31] reported that after reoperation, the incidence of transient RLN injury was $0-22 \%$ and of permanent RLN injury was $0-13 \%$ [31]. The incidence rates of transient and permanent hypoparathyroidism were $56.6 \%$ and $10 \%$, respectively [4]. However, in this study, no life-threatening complications or sequelae were observed after RFA. This was consistent with the findings of a recent meta-analysis that showed the complication rate after RFA was only $1.44 \%$ [32]. There were several reasons for the low incidence of complications after RFA. First, during the RFA procedure, real-time US imaging allowed the physician to ablate the target nodule accurately while carefully monitoring the critical structures [33]. Second, the RFA procedure was performed by an experienced US physician. The experience of the physician was found to be an important factor for preventing thermal injury to the critical structures or nerves [7], particularly in patients with a distorted anatomy and postoperative adhesions from the initial surgery. Third, the moving-shot technique and hydrodissection technique were used during the RFA procedure, which have been verified as safe methods for ablating the nodule margin and preventing thermal injury [7].

Due to the different types of the initial thyroid surgery as well as different sizes of the postoperative nodules, reoperation may involve partial or total thyroidectomy. Patients often need life-long thyroid hormone supplementation, which leads to adverse effects on the bones and the cardiovascular systems [1, 2, 34]. Since only the targeted nodule was ablated via real-time US monitoring, the incidence of permanent hypothyroidism after RFA was only $0.04 \%(1 / 2245)$ [32]. Ha et al. [23] reported that RFA did not affect thyroid function in patients with postoperative benign thyroid nodules. In the present study, the thyroid function of the patients was well maintained, and no patient developed hypothyroidism after RFA. Hypothyroidism after RFA was rare, and the main cause of hypothyroidism seems to be a progression of autoimmune thyroiditis associated with preexisting thyroid antibodies [23]. Although the probability of immunological activation and subsequent hypothyroidism after ablation was low, patients with thyroid antibodies before treatment should be informed the possibility of hypothyroidism.

In this study, bipolar RFA was used for treatment, because it had more advantages than monopolar RFA, especially when used in sensitive cervical areas [35-38]. Monopolar RFA required a grounding pad so that the electrical current could flow between the electrode and the grounding pad, which could lead to painful skin burns, interfer with implanted cardiac devices, and could limit the efficiency when placed incorrectly [35-38]. In contrast, in bipolar systems, the electric current was limited to the applicator tip, which could eliminate the side effects of monopolar RFA [36], resulting in a lower risk complication [8]. Moreover, monopolar RFA lost more energy to the tissue within the electrical circuit because of the higher distance to the grounding pole; thus it was more likely to stimulate sensory nerve structures and consequentially cause pain [36].

There were some limitations of this study. Firstly, it was a single-center retrospective study. Secondly, the sample size was small, and the follow-up time was relatively short. Thirdly, benign confirmation of the postoperative thyroid nodules was carried out via two separate FNAs or CNBs. False negative results or the presence of occult microcarcinoma could not be completely excluded. Lastly, because the thyroid function before RFA was normal in all patients, thyroid antibody tests were not performed after RFA. 


\section{Conclusions}

As a minimally invasive modality, RFA was a safe, effective and thyroid function- preserving option for patients with symptomatic benign thyroid nodule after a previous lobectomy.

\author{
Abbreviations \\ RFA: Radiofrequency ablation; VRR: Volume reduction rate; FNA: Fine-needle \\ aspiration; CNB: Core-needle biopsy; RLN: Recurrent laryngeal nerve.
}

\section{Acknowledgements}

Not applicable

\section{Authors' contributions}

$\mathrm{YL}$ interpreted the patient data and drafted the manuscript; ZMB and XF participated in the patient enrollment and conceived the study. MJ and JX collected patient data; LYK performed the RFA procedure, conceived the study and participated in its coordination. All authors read and approved the final manuscript.

\section{Funding}

This study is supported by Beijing Municipal Science \& Technology Commission (No. Z181100001718017) and the Research of Healthcare Big Data of Chinese PLA General Hospital (2019MBD-040).

\section{Availability of data and materials}

The datasets generated and/or analyzed during the current study are not publicly available due patient privacy but are available from the corresponding author on reasonable request.

\section{Ethics approval and consent to participate}

The Institutional Review Board of our institution approved this retrospective study. All the patients were provided written information consent before RFA All the methods were performed in accordance with the relevant guidelines and regulations.

\section{Consent for publication}

Not applicable.

\section{Competing interests}

The authors declare that they have no competing interests.

Received: 26 November 2020 Accepted: 2 February 2021

Published online: 11 March 2021

\section{References}

1. Gharib H, Papini E, Paschke R, Duick DS, Valcavi R, Hegedus L, et al. American Association of Clinical Endocrinologists, Associazione Medici Endocrinologi, and European Thyroid Association medical guidelines for clinical practice for the diagnosis and management of thyroid nodules. J Endocrinol Invest. 2010;33(5 Suppl):1-50.

2. Haugen BR, Alexander EK, Bible KC, Doherty GM, Mandel SJ, Nikiforov YE, et al. 2015 American Thyroid Association Management guidelines for adult patients with thyroid nodules and differentiated thyroid cancer: The American Thyroid Association Guidelines Task force on thyroid nodules and differentiated thyroid cancer. Thyroid. 2015;26(1):1-133.

3. Phitayakorn R, McHenry CR. Follow-up after surgery for benign nodular thyroid disease: evidence-based approach. World J Surg. 2008;32(7):1374-84.

4. Medas F, Tuveri M, Canu GL, Erdas E, Calo PG. Complications after reoperative thyroid surgery: retrospective evaluation of 152 consecutive cases. Updates Surg. 2019;71(4):705-10.

5. Lefevre JH, Tresallet C, Leenhardt L, Jublanc C, Chigot JP, Menegaux F. Reoperative surgery for thyroid disease. Langenbecks Arch Surg. 2007;392(6):685-91.
6. Terris DJ, Khichi S, Anderson SK, Seybt MW. Reoperative thyroidectomy for benign thyroid disease. Head Neck. 2010;32(3):285-9.

7. Kim JH, Baek JH, Lim HK, Ahn HS, Baek SM, Choi YJ, et al. 2017 Thyroid radiofrequency ablation guideline: Korean Society of Thyroid Radiology. Korean J Radiol. 2018;19(4):632-55.

8. Dietrich CF, Müller T, Bojunga J, Dong Y, Mauri G, Radzina M, et al. Statement and recommendations on interventional ultrasound as a thyroid diagnostic and treatment procedure. Ultrasound Med Biol. 2018:44(1):14-36.

9. Papini E, Pacella CM, Solbiati LA, Achille G, Barbaro D, Bernardi S, et al. Minimally-invasive treatments for benign thyroid nodules: a Delphi-based consensus statement from the Italian minimally-invasive treatments of the thyroid (MITT) group. Int J Hyperthermia. 2019;36(1):376-82.

10. Ha EJ, Baek JH, Che Y, Chou YH, Fukunari N, Kim JH, et al. Radiofrequency ablation of benign thyroid nodules: recommendations from the Asian Conference on Tumor Ablation Task Force. Ultrasonography. 2020.

11. Papini E, Monpeyssen H, Frasoldati A, Hegedüs L. 2020 European thyroid association clinical practice guideline for the use of image-guided ablation in benign thyroid nodules. Eur Thyroid J. 2020;9(4):172-85.

12. Kotewall $\mathrm{N}$, Lang $\mathrm{BHH}$. High-intensity focused ultrasound ablation as a treatment for benign thyroid diseases: the present and future. Ultrasonography. 2019;38(2):135-42.

13. Lim HK, Lee JH, Ha EJ, Sung JY, Kim JK, Baek JH. Radiofrequency ablation of benign non-functioning thyroid nodules: 4-year follow-up results for 111 patients. Eur Radiol. 2013;23(4):1044-9.

14. Guang Y, He W, Luo Y, Zhang H, Zhang Y, Ning B, et al. Patient satisfaction of radiofrequency ablation for symptomatic benign solid thyroid nodules: our experience for 2-year follow up. BMC Cancer. 2019;19(1):147.

15. Lee GM, You JY, Kim HY, Chai YJ, Kim HK, Dionigi G, et al. Successful radiofrequency ablation strategies for benign thyroid nodules. Endocrine. 2019;64(2):316-21.

16. Tang X, Cui D, Chi J, Wang Z, Wang T, Zhai B, et al. Evaluation of the safety and efficacy of radiofrequency ablation for treating benign thyroid nodules. J Cancer. 2017;8(5):754-60

17. Trimboli P, Castellana M, Sconfienza LM, Virili C, Pescatori LC, Cesareo $\mathrm{R}$, et al. Efficacy of thermal ablation in benign non-functioning solid thyroid nodule: a systematic review and meta-analysis. Endocrine. 2019;67(1):35-43.

18. Cesareo R, Pasqualini V, Simeoni C, Sacchi M, Saralli E, Campagna G, et al. Prospective study of effectiveness of ultrasound-guided radiofrequency ablation versus control group in patients affected by benign thyroid nodules. J Clin Endocrinol Metab. 2015;100(2):460-6.

19. Spiezia S, Garberoglio R, Milone F, Ramundo V, Caiazzo C, Assanti AP, et al. Thyroid nodules and related symptoms are stably controlled two years after radiofrequency thermal ablation. Thyroid. 2009;19(3):219-25.

20. Faggiano A, Ramundo V, Assanti AP, Fonderico F, Macchia PE, Misso $C$, et al. Thyroid nodules treated with percutaneous radiofrequency thermal ablation: a comparative study. J Clin Endocrinol Metab. 2012:97(12):4439-45.

21. Kim YS, Rhim H, Tae K, Park DW, Kim ST. Radiofrequency ablation of benign cold thyroid nodules: initial clinical experience. Thyroid. 2006;16(4):361-7.

22. Deandrea M, Trimboli P, Garino F, Mormile A, Magliona G, Ramunni MJ, et al. Long-term efficacy of a single session of RFA for benign thyroid nodules: a longitudinal 5-year observational study. J Clin Endocrinol Metab. 2019;104(9):3751-6.

23. Ha EJ, Baek JH, Lee JH, Sung JY, Lee D, Kim JK, et al. Radiofrequency ablation of benign thyroid nodules does not affect thyroid function in patients with previous lobectomy. Thyroid. 2013;23(3):289-93.

24. Kim HJ, Park KN, Lee SW. The efficacy of ultrasonography-guided radiofrequency ablation in patients with benign thyroid goiters with a history of unilateral lobectomy. Clin Exp Otorhinolaryngol. 2020.

25. Zatelli MC, Lamartina L, Meringolo D, Arvat E, Damiani L, Grani G, et al. Thyroid nodule recurrence following lobo-isthmectomy: incidence, patient's characteristics, and risk factors. J Endocrinol Invest. 2018:41(12):1469-75.

26. Sidhu PS, Cantisani V, Dietrich CF, Gilja OH, Saftoiu A, Bartels E, et al. The EFSUMB guidelines and recommendations for the clinical practice of contrast-enhanced ultrasound (CEUS) in non-hepatic applications: update 2017 (short version). Ultraschall Med. 2018;39(2):154-80. 
27. Mauri G, Pacella CM, Papini E, Solbiati L, Goldberg SN, Ahmed M, et al. Image-guided thyroid ablation: proposal for standardization of terminology and reporting criteria. Thyroid. 2019;29(5):611-8.

28. Yan L, Luo Y, Xie F, Zhang M, Xiao J. Residual vital ratio: predicting regrowth after radiofrequency ablation for benign thyroid nodules. Int J Hyperthermia. 2020;37(1):1139-48.

29. Sim JS, Baek JH, Lee J, Cho W, Jung SI. Radiofrequency ablation of benign thyroid nodules: depicting early sign of regrowth by calculating vital volume. Int J Hyperthermia. 2017:33(8):905-10.

30. Pelizzo MR, Variolo M, Bernardi C, Izuzquiza M, Piotto A, Grassetto G, et al. Complications in thyroid resurgery: a single institutional experience on 233 patients from a whole series of 4752 homogeneously treated patients. Endocrine. 2014;47(1):100-6.

31. Hardman JC, Smith JA, Nankivell P, Sharma N, Watkinson JC. Re-operative thyroid surgery: a 20-year prospective cohort study at a tertiary referral centre. Eur Arch Otorhinolaryngol. 2015;272(6):1503-8.

32. Chung SR, Suh $\mathrm{CH}$, Baek JH, Park HS, Choi YJ, Lee JH. Safety of radiofrequency ablation of benign thyroid nodules and recurrent thyroid cancers: a systematic review and meta-analysis. Int J Hyperthermia. 2017:33(8):920-30.

33. Che Y, Jin S, Shi C, Wang L, Zhang X, Li Y, et al. Treatment of benign thyroid nodules: comparison of surgery with radiofrequency ablation. AJNR Am J Neuroradiol. 2015;36(7):1321-5.
34. Haugen BR. 2015 American Thyroid Association Management guidelines for adult patients with thyroid nodules and differentiated thyroid cancer: what is new and what has changed? Cancer. 2017;123(3):372-81.

35. Korkusuz Y, Mader A, Gröner D, Ahmad S, Mader OM, Grünwald F, et al. Comparison of mono- and bipolar radiofrequency ablation in benign thyroid disease. World J Surg. 2017;41(10):2530-7.

36. Li XL, Xu HX, Lu F, Yue WW, Sun LP, Bo XW, et al. Treatment efficacy and safety of ultrasound-guided percutaneous bipolar radiofrequency ablation for benign thyroid nodules. Br J Radiol. 2016;89(1059):20150858.

37. Ritz JP, Lehmann KS, Schumann T, Knappe V, Zurbuchen U, Buhr HJ, et al. Effectiveness of various thermal ablation techniques for the treatment of nodular thyroid disease-comparison of laser-induced thermotherapy and bipolar radiofrequency ablation. Lasers Med Sci. 2011;26(4):545-52.

38. Holmer C, Lehmann KS, Knappe V, Zurbuchen U, Frericks B, Schumann $T$, et al. Bipolar radiofrequency ablation for nodular thyroid disease-ex vivo and in vivo evaluation of a dose-response relationship. J Surg Res. 2011;169(2):234-40.

\section{Publisher's Note}

Springer Nature remains neutral with regard to jurisdictional claims in published maps and institutional affiliations.
Ready to submit your research? Choose BMC and benefit from:

- fast, convenient online submission

- thorough peer review by experienced researchers in your field

- rapid publication on acceptance

- support for research data, including large and complex data types

- gold Open Access which fosters wider collaboration and increased citations

- maximum visibility for your research: over $100 \mathrm{M}$ website views per year

At BMC, research is always in progress.

Learn more biomedcentral.com/submissions 